\title{
p27 modulates tropism of mesenchymal stem cells toward brain tumors
}

\author{
YUN GAO $^{1,5}$, CHUNYU GU ${ }^{1,3}$, SHAOYI LI $^{1,3}$, TSUTOMU TOKUYAMA $^{1}$, NAOKI YOKOTA ${ }^{1}$, \\ KEIICHI I. NAKAYAMA ${ }^{4}$, MASATOSHI KITAGAWA ${ }^{2}$ and HIROKI NAMBA ${ }^{1}$
}

\begin{abstract}
Departments of ${ }^{1}$ Neurosurgery and ${ }^{2}$ Biochemistry, Hamamatsu University School of Medicine, Hamamatsu 431-3192, Japan;
${ }^{3}$ Department of Neurosurgery, Shengjing Hospital of China Medical University, Shenyang 110004, P.R. China;

${ }^{4}$ Department of Molecular and Cellular Biology, Medical Institute of Bioregulation,

Kyushu University, Fukuoka 812-8582, Japan
\end{abstract}

Received March 10, 2010; Accepted April 28, 2010

DOI: 10.3892/etm_00000107

\begin{abstract}
Mesenchymal stem cells (MSCs) have inherent tumor-tropic properties in the brain and seem to be a useful tool for cellular therapy for brain tumors. However, the mechanisms involved in MSC migration are not fully understood. The tumor suppressor p27, an inhibitor of cyclin-dependent kinase complexes, not only plays a crucial role in cell cycle regulation but also has cell cycle-independent functions, such as differentiation and migration of cells. In fact, p27 has been alternatively reported to inhibit or stimulate cell migration in cells of different types. Therefore, in the present study, we investigated whether p27 is involved in the tumortropic activity of MSCs using MSCs from p27-null mice. It was found that $\mathrm{p} 27^{-/-}$MSCs showed a decreased motility in the wound healing assay and displayed increased numbers of stress fibers. To compare the in vivo migratory activity of p27 $7^{-/}$and p27+/+ MSCs toward glioma, we injected C6 glioma cells into one side of the mouse brain and BrdU-labeled p2 $7^{-1-}$ or $\mathrm{p} 27^{+/+} \mathrm{MSCs}$ into the other side. Significantly fewer labeled p27-/ MSCs were observed in the tumor area compared with p2 $7^{+/+}$MSCs. The present study suggests that p27 works as a stimulator of the in vitro and in vivo migration process of MSCs toward tumors. These findings are important when the efficacy of stem cell-based strategies for glioma therapy is considered.
\end{abstract}

Correspondence to: DrHirokiNamba, Department of Neurosurgery, Hamamatsu University School of Medicine, 1-20-1 Handayama, Higashi-ku, Hamamatsu 431-3192, Japan

E-mail: hnamba@hama-med.ac.jp

Present address: ${ }^{5}$ Endocrine Department and Institute of Endocrinology, First Affiliated Hospital of China Medical University, Shenyang, P.R. China

Key words: mesenchymal stem cell, brain tumor, migration, p27

\section{Introduction}

Glioblastomas, the most common primary malignant brain tumors, infiltrate the surrounding normal brain tissues, and therefore are almost always non-curable even with surgical resection. Despite recent refined therapeutic strategies, the regrowth of tumor cells residing in the adjacent brain inevitably occurs, resulting in a dismal prognosis for patients with glioblastoma (1). Recently, mesenchymal stem cells (MSCs) that have inherent tumor-tropic properties have been tested as a vehicle for delivery of therapeutic genes such as suicide genes and cytokine genes in experimental gliomas (2-13). MSCs used as a vehicle for suicide gene therapy have obtained sufficiently effective results both in intracranial glioma (14) and in the leptomeningeal glioma models (15). However, little is known about the mechanisms involved in the migratory activity of MSCs toward tumors.

Cyclin-dependent kinase (CDK) inhibitor p27 Kipl is a well-characterized tumor suppressor and is frequently downregulated by enhanced degradation of p27 in malignancies. The decreased expression of p27 is usually correlated with increased tumor aggressiveness and poor clinical outcome. Notably, high p27 levels correlate with high tumor grade, poor prognosis and increased metastasis. This has been observed, for instance, in various types of tumors (breast, cervix, esophagus and uterus) and in certain types of lymphomas and leukemias (16-18). These observations suggest that deregulation of p27 in tumors may serve to uncouple it from its cell cycle-inhibitory function, possibly by being excluded from the nucleus. Once in the cytoplasm, p27 may exert other functions, such as the regulation of cell migration, thereby promoting tumor progression and invasiveness $(19,20)$.

When MSCs are used as a vehicle for glioma gene therapy, highly migratory MSCs would be more efficient. However, little is known about whether p27 is involved in the tumortropic properties of MSCs. In the present study, we investigated the influence of p27 on MSC migration by using MSCs derived from p27-null and wild-type mice and found that the motility of $\mathrm{p} 27^{-/-}$MSCs was impaired and the numbers of actin stress fibers of these cells were increased. The in vivo migratory 
activity of the $\mathrm{p} 27^{-/}$MSCs toward the tumor in the mouse brain was lower than that of the $\mathrm{p} 27^{+/+}$MSCs, suggesting that $\mathrm{p} 27$ acted as a stimulator during the migration process of MSCs.

\section{Materials and methods}

Isolation and culture of MSCs. All following experiments were performed according to the Rules of Animal Experimentation and the Guide for the Care and Use of Laboratory Animals of the Hamamatsu University School of Medicine. p2 $7^{-/}$and p2 $7^{+/+}$C57BL/6 mice ( 8 weeks old) were sacrificed with ether, and the marrow tissue was obtained from the femurs and tibias as previously described (21). A single-cell suspension was obtained by gently aspirating the tissue several times using the same needle and syringe in $5 \mathrm{ml}$ Murine MSC Growth Medium (MMSCGM; StemCell Technologies Inc., British Columbia, Canada), washed one time with $10 \mathrm{ml}$ fresh MMSCGM and passed through a 70- $\mu$ m nylon strainer (Falcon, Becton Dickinson Labware, Franklin lakes, NJ, USA). The cells were then plated into a $25-\mathrm{cm}^{2}$ tissue culture flask in $5 \mathrm{ml}$ MMSCGM and incubated at $37^{\circ} \mathrm{C}$ under $5 \%$ $\mathrm{CO}_{2}$. The non-adherent cells were removed by replacing the medium $24 \mathrm{~h}$ after the initial culture. The residual attached cells were maintained at $37^{\circ} \mathrm{C}$ in $5 \% \mathrm{CO}_{2}$ by exchanging the medium with fresh medium at 5-day intervals. These cells are designated as MSCs in the present study.

Wound healing assay. Cells were seeded at $80 \%$ confluence in $60-\mathrm{mm}$ dishes and grown for an additional $24 \mathrm{~h}$. A linear scratch, $\sim 1 \mathrm{~cm}$ wide, was performed using a rubber policeman across the diameter of the plate. This was then rinsed with phosphate-buffered saline (PBS). Cells were fed with growth medium supplement. Cells were incubated for $24 \mathrm{~h}$, rinsed with PBS, and fixed for $5 \mathrm{~min}$ in $95 \%$ ethanol $/ 5 \%$ acetic acid at room temperature. For each plate, images were captured using a dissection microscope (Zeiss) at a magnification of $\mathrm{x} 20$. Then the distance the cells had migrated from the scratch line at each time point was measured in $\mathrm{mm}$. Cells were pretreated with $10 \mu \mathrm{g} / \mathrm{ml}$ mitomycin $\mathrm{C}$ for $3 \mathrm{~h}$ to block cell division in order to rule out the possibility that the differences in motility were due to the differences in cell proliferation.

BrdU labeling and immunohistological analysis. For the in vivo transplantation experiments, MSC cultures grown for 5 days were pulsed for $48 \mathrm{~h}$ with $5 \mu \mathrm{M}$ 5-bromo-2-deoxyuridine (BrdU) (Sigma) in Eagle's minimal essential medium supplemented with $10 \%$ FBS or for $24 \mathrm{~h}$ with $10 \mu \mathrm{g} / \mathrm{ml}$ bisbenzimide (Sigma) before harvest (22). Cells were harvested by incubation with $0.25 \%$ trypsin for $5 \mathrm{~min}$ at room temperature followed by gentle scraping. For BrdU immunostaining, the DNA was first denatured by incubating the brain sections $(6 \mu \mathrm{m})$ in $50 \%$ formamide $2 \mathrm{X} \mathrm{SSC}$ at $65^{\circ} \mathrm{C}$ for $2 \mathrm{~h}$ and then in $2 \mathrm{~N} \mathrm{HCl}$ at $37^{\circ} \mathrm{C}$ for $30 \mathrm{~min}$. The sections were then rinsed with PBS and treated with $1 \% \mathrm{H}_{2} \mathrm{O}_{2}$ to block endogenous peroxidase. The sections were incubated with a mouse monoclonal antibody agaist BrdU (1:500, Sigma) overnight and incubated with biotinylated secondary antibody (Dako) for $1 \mathrm{~h}$. Control experiments consisted of staining brain coronal tissue sections as described above, but the primary antibodies were omitted.
In vivo migratory capacity of MSCs toward brain tumors in nude mice. To compare the in vivo migratory capacity and tropism of p27-/- and p27 $7^{+/+}$MSCs toward glioma, we injected $2 \times 10^{4} \mathrm{C} 6$ rat glioma cells into one side of the mouse brain hemisphere and $1 \times 10^{5}$ BrdU-labeled MSCs into the opposite hemisphere. The method of cell implantation was the same as described previously (21). Briefly, $10 \mathrm{BALB} / \mathrm{c}$ nude mice (6 weeks old, Nippon SLC, Hamamatsu, Japan) were anesthetized with $0.4 \mathrm{ml} / 100 \mathrm{~g}$ equithesin and placed in a stereotaxic apparatus (Narishige Scientific Instrument Lab., Tokyo, Japan). A 25 -gauge needle was inserted into the target point $(0.2 \mathrm{~mm}$ posterior to the bregma, $2 \mathrm{~mm}$ left of the midline, $3 \mathrm{~mm}$ ventral from the dura), and $2 \times 10^{4} \mathrm{C} 6$ cells were injected with a 10- $\mu$ l microsyringe (Hamilton Company, Reno, NV, USA) and a microinjector (Harvard Apparatus Inc., South Natick, MA, USA) for $5 \mathrm{~min}$. After one week, $2 \times 10^{4}$ BrdU-labeled MSCs (p27 $7^{-/}$or $\mathrm{p} 27^{+/+}, \mathrm{n}=5$ for each group) were injected at the mirror point in the contralateral hemisphere $(0.2 \mathrm{~mm}$ posterior, $2 \mathrm{~mm}$ right). The animals were sacrificed on day 10 . Serial coronal sections ( $5 \mu \mathrm{m})$ were obtained and stained with hematoxylin and eosin, and the tumor area of each section was measured using NIH Image software (rsbweb.nih.gov). The adjacent sections were stained with the BrdU antibody as described above, and the MSC infiltrating area was detected. The migration potential of MSCs was defined as the MSC infiltration area/C6 tumor region.

\section{Results}

p27-1- MSCs exhibit no different morphological characteristics but have elevated growth. The murine p2 $7^{\text {Kipl }}$ genomic locus comprises three exons spanning $\sim 4 \mathrm{~kb}$. The targeting construct was designed to delete the exon 1 and 2 of the p27 Kipl gene, since the protein-coding region resides only in exons 1 and 2 (23). MSCs were isolated from $\mathrm{p} 27^{-/}$and $\mathrm{p} 27^{+/+}$mice as described in Materials and methods. There was no difference in the morphological characteristics between $\mathrm{p} 27^{-/}$and $\mathrm{p} 27^{+/+}$ MSCs, but the $\mathrm{p} 27^{-/}$MSCs had an elevated proliferation rate compared to $\mathrm{p} 27^{+/+}$MSCs due to the function of p27 as an inhibitor of CDK. The doubling growth time of $\mathrm{p} 27^{+/+} \mathrm{MSCs}$ $(122 \mathrm{~h})$ was more than twice that of p27- MSCs $(60 \mathrm{~h})$.

Impaired motility in $22^{-/-}$MSCs. To further characterize the function of p27 during MSC migration, the motility of MSCs derived from $\mathrm{p} 27^{-/}$and $\mathrm{p} 27^{+/+}$mice was measured using the wound healing assay. The wound healing assay was designed as a method of simulating the ability of a cell to reconstruct a tissue. Cell motility in this assay system is dependent upon reorganization of the actin cytoskeleton and the assembly and disassembly of focal adhesion complexes, processes which are governed by the Rho family GTPases Rho, Rac and Cdc42 (24). Following wounding of a confluent cell monolayer, p27-- MSCs exhibited a significant reduction in cell motility compared with cells derived from wild-type MSCs $24 \mathrm{~h}$ later $(\mathrm{p}<0.05$, Fig. 1).

Increased numbers of actin stress fibers in p27-1- MSCs. It was reported that $\mathrm{p} 27^{-1-}$ fibroblasts have elevated amounts of endogenous Rho-GTP due to inhibition of RhoA by p27. p27-1fibroblasts had Rho-dependent cellular phenotypes, including 

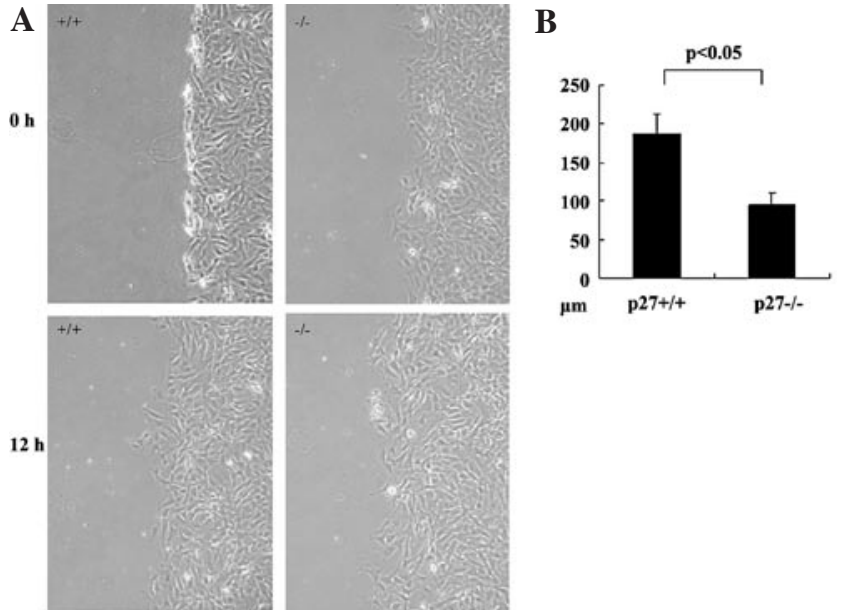

Figure 1. p2 $27^{-}$MSCs exhibit a migration deficit in the wound healing assay. (A) Migration of $\mathrm{p} 27^{+/+}$and $\mathrm{p} 27^{-/}$MSCs following wounding of a confluent cell monolayer, $\mathrm{x} 20$. (B) The distance migrated from the scratch line by the cells is significantly shorter in p27/- MSCs than in p27 $7^{+/+}$MSCs (triplicate, mean \pm standard error, $\mathrm{p}<0.05$ ).

\section{$0.1 \%$ FCS 48 h}

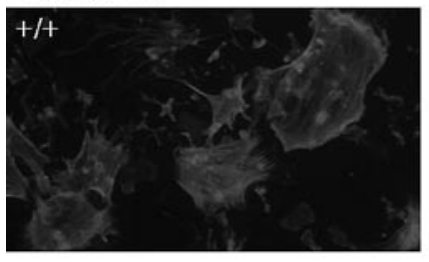

FGF 40 min

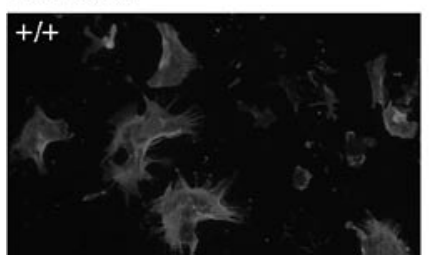

Figure 2. p2 $7^{-/}$MSCs have increased numbers of actin stress fibers. (Top) MSCs were seeded on glass coverslips and allowed to grow for $16 \mathrm{~h}$, then starved for $48 \mathrm{~h}$ in $0.1 \%$ BSA. (Bottom) After starvation, MSCs were stimulated for $40 \mathrm{~min}$ with $25 \mathrm{ng} / \mathrm{ml} \mathrm{FGF}$. Actin was visualized with phalloidin-rhodamine $(1 / 500)$

increased numbers of focal adhesions and actin stress fibers, increased phosphorylation of cofilin (a target molecule of the Rho pathway), and a marked decrease in motility (25). We therefore surveyed the actin cytoskeleton of $\mathrm{p} 27^{-/}$and p27+/+ MSCs by immunocytochemistry using phalloidin. Since various cytokines (including EPO, IL-6, SDF1- $\beta$, FGF and VEGF) showed the ability to increase the migratory activity of MSCs, we analyzed the effects of FGF on the actin cytoskeleton. Wild-type MSCs had few actin stress fibers in serum-starved conditions, and FGF stimulation evoked a dramatic rearrangement of the actin cytoskeleton (Fig. 2, left). In contrast, $\mathrm{p} 27^{--}$cells had an extensive network of stress fibers in the absence of serum, and FGF stimulation substantially failed to induce the actin rearrangement (Fig. 2, right).

Decreased in vivo migratory capacity of p27- MSCs toward tumors. MSCs have the capacity to migrate specifically toward

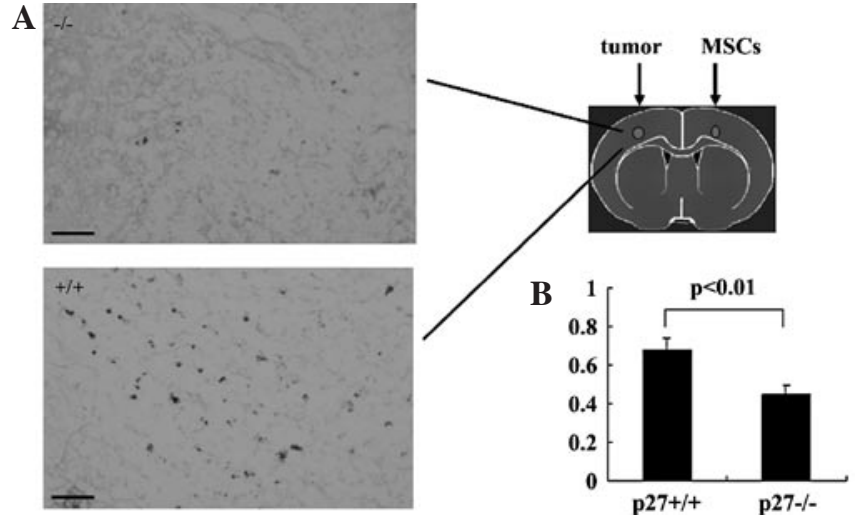

Figure 3. p2 $7^{-/}$MSCs exhibit a migration deficit toward the tumor region in vivo. (A) BrdU-labeled MSCs migrating from the opposite hemisphere entered the tumor region as detected using the BrdU antibody (brownstained cells). (B) The ratio of the area of the BrdU-labeled MSC infiltration region divided by the area of the tumor region is significantly lower in $\mathrm{p} 27^{-1}$ MSCs compared with $27^{+/+}$MSCs $(n=5$ for each group, mean \pm standard error, $\mathrm{p}<0.01)$.

tumors. To further compare the tropism of $\mathrm{p} 27^{-1-}$ and $\mathrm{p} 27^{+/+}$ MSCs, we detected their migratory capacity toward tumors. We injected BrdU-labeled MSCs on the opposite hemisphere of the tumor inoculation. MSCs migrated across the corpus callosum toward the tumor and ultimately entered the tumor on the opposite side of the brain (Fig. 3A). We compared the tropism and infiltrative potential of p27+/+ and p27- MSCs using the ratio of the area of the BrdU-labeled MSC infiltration region divided by the area of the tumor region. We found significantly fewer labeled $\mathrm{p} 27^{--} \mathrm{MSCs}$ in the tumor compared with $\mathrm{p} 27^{+/+}$MSCs $\left(\mathrm{p}<0.01\right.$, Fig. 3B). Very few $\mathrm{p} 27^{+++}$MSCs were found in the normal brain tissue beyond the injection site.

\section{Discussion}

Since Aboody and colleagues (26) first demonstrated the potent migratory ability of neural stem cells to brain tumors, this ability of neural stem cells has been confirmed by numerous studies, including ours (27). It has also been demonstrated that an established rat glioma can be successfully treated by genetically engineered neural stem cells (21). However, there is a limitation to using neural stem cells obtained from the patients with glioblastomas due to the invasiveness and the low proliferative activity of neural stem cells obtained from adult brains. As an alternative, we have been testing the use of MSCs obtained from the bone marrow of patients instead of neural stem cells. It has previously been demonstrated that rat brain tumors can be effectively treated by rat MSCs transduced with the herpes simplex virus-thymidine kinase gene, the same gene we used with neural stem cells (14). If MSCs can be used for the treatment of malignant glioma that deeply infiltrates the surrounding normal brain tissues, the potency of the tumor-homing activity of MSCs is particularly important for the success of this treatment strategy. However, the precise mechanisms of tumor tropism of neural and other types of stem cells are still unknown. Some recent reports suggest several molecular mechanisms of MSC migration 
toward gliomas (28-30). p27, a CDK inhibitor, has also been known to regulate cell migration as well as cell proliferation. Therefore, in the present study we investigated the role of p27 on the migratory activity of MSCs.

We measured the motility of MSCs derived from p27-null mouse using a wound healing assay and found that $\mathrm{p} 27^{--}$MSCs had decreased motility and increased numbers of actin stress fibers. Consistent with the results in mouse embryonic fibroblasts, p27 works as a stimulator during the migratory process of MSCs via modulation of the Rho pathway (25). MSCs are known to have strong tropism toward tumors, and when MSCs are implanted in one hemisphere and tumor cells in the other hemisphere, most MSCs travel across the corpus callosum and gather around the tumor $(5,8,9,12,13,31)$. Our in vivo study, using a contralateral hemisphere injection model, demonstrated that the migratory activity of MSCs toward tumors was also significantly decreased in $227^{-/}$MSCs.

p27 generally suppresses CDK activity in proliferating cells. Another role of p27 in cell migration has been recently suggested in vitro. However, the physiological importance of p27 in cell migration remains elusive, since p27-deficient mice have no obvious migration defect-related phenotypic abnormality. p27 has been alternatively reported as an inhibitor or stimulator of cell migration in primary or stabilized cells of different origins. Controversial results for the role of p27 in cell motility are mainly attributable to both types of cells and the methods of motility assay used. Cell migration is a dynamic process governed by intracellular and extracellular stimuli that promote the formation of focal adhesions between the cell membrane and the extracellular matrix. In some cell types p27 increases cell motility, whereas in others it decreases it. These differences possibly originate from cell type-specific variation in the relative balance between Rho and Rac activity.

Motility assays mainly consist of the fibronectin-coated transwell assay and the wound healing assay. Cell migration through the pores of fibronectin-coated transwells is promoted by amoeboid movement that responds to attractant stimuli lacking an obvious polarization, which depends largely on propulsive forces and on cytoplasmic streaming for their motility (32). In this case, p27 may act as an inhibitor of cell migration by altering microtubule stability, which then impairs the cytoskeletal modifications necessary for the cell to move. The wound healing assay is an in vitro directional motility assay designed to simulate the ability of cells to reconstruct tissues. It is possible that p27, contributing to stabilize the perinuclear network of microtubules, enforces cell polarity and favors the movements of highly polarized cells. p27-- fibroblasts failed to reorient glutamylated microtubules to the scratched area during the wound healing assay, since they migrated toward the wounded area with altered cell trajectories (33). Accordingly, p27 expression stimulates wound healing cell motility by decreasing the RhoA-ROCK1 activity and inhibits the Rho pathway by blocking the guanine-nucleotide exchange-mediated activation of Rho (25).

Our data suggested that p27 increases cell migration under both in vitro and in vivo conditions as shown previously (25). It seems that $\mathrm{p} 27$ regulates the migration process of MSCs via modulation of the Rho pathway, since p27-- MSCs showed increased numbers of stress fibers and were largely refractory to FGF stimuli. p27 may be acting as a tumor suppressor and as an oncogene, depending on its subcellular localization, which may explain the different regulatory functions of p27 in different cell lines. The results of the present study would open a window on the mechanisms contributing to the regulation of MSCs migration, though further studies are obviously required to understand the behaviors of stem cells in the brain. We believe that knowledge of the mechanisms involved in the migratory process and enhancement of the potency of MSC migration are directly related to the efficacy of stem cell-based strategies for glioma therapy.

\section{References}

1. DeAngelis LM: Brain tumors. N Engl J Med 344: 114-123, 2001.

2. Kim SM, Lim JY, Park SI, et al: Gene therapy using TRAILsecreting human umbilical cord blood-derived mesenchymal stem cells against intracranial glioma. Cancer Res 68: 9614-9623, 2008.

3. Kinoshita Y, Kamitani H, Mamun MH, et al: A gene delivery system with a human artificial chromosome vector based on migration of mesenchymal stem cells towards human glioblastoma HTB14 cells. Neurol Res, 2009 (E-pub ahead of print).

4. Kucerova L, Altanerova V, Matuskova M, Tyciakova S and Altaner C: Adipose tissue-derived human mesenchymal stem cells mediated prodrug cancer gene therapy. Cancer Res 67: 6304-6313, 2007.

5. Lee J, Elkahloun AG, Messina SA, et al: Cellular and genetic characterization of human adult bone marrow-derived neural stem-like cells: a potential antiglioma cellular vector. Cancer Res 63: 8877-8889, 2003.

6. Menon LG, Kelly K, Yang HW, Kim SK, Black PM and Carroll RS: Human bone marrow-derived mesenchymal stromal cells expressing S-TRAIL as a cellular delivery vehicle for human glioma therapy. Stem Cells 27: 2320-2330, 2009.

7. Miletic H, Fischer YH, Litwak S, et al: Bystander killing of malignant glioma by bone marrow-derived tumor-infiltrating progenitor cells expressing a suicide gene. Mol Ther 15: 1373-1381, 2007.

8. Nakamizo A, Marini F, Amano T, et al: Human bone marrowderived mesenchymal stem cells in the treatment of gliomas. Cancer Res 65: 3307-3318, 2005.

9. Nakamura K, Ito Y, Kawano Y, et al: Antitumor effect of genetically engineered mesenchymal stem cells in a rat glioma model. Gene Ther 11: 1155-1164, 2004.

10. Sasportas LS, Kasmieh R, Wakimoto H, et al: Assessment of therapeutic efficacy and fate of engineered human mesenchymal stem cells for cancer therapy. Proc Natl Acad Sci USA 106: 4822-4827, 2009.

11. Uchibori R, Okada T, Ito T, et al: Retroviral vector-producing mesenchymal stem cells for targeted suicide cancer gene therapy. J Gene Med 11: 373-381, 2009.

12. Wu X, Hu J, Zhou L, et al: In vivo tracking of superparamagnetic iron oxide nanoparticle-labeled mesenchymal stem cell tropism to malignant gliomas using magnetic resonance imaging. Laboratory investigation. J Neurosurg 108: 320-329, 2008.

13. Yuan X, Hu J, Belladonna ML, Black KL and Yu JS: Interleukin23-expressing bone marrow-derived neural stem-like cells exhibit antitumor activity against intracranial glioma. Cancer Res 66: 2630-2638, 2006.

14. Amano S, Li S, Gu C, et al: Use of genetically engineered bone marrow-derived mesenchymal stem cells for glioma gene therapy. Int J Oncol 35: 1265-1270, 2009.

15. Gu C, Li S, Tokuyama T, Yokota N and Namba H: Therapeutic effect of genetically engineered mesenchymal stem cells in rat experimental leptomeningeal glioma model. Cancer Lett 298: 256-262, 2010.

16. Bloom J and Pagano M: Deregulated degradation of the cdk inhibitor p27 and malignant transformation. Semin Cancer Biol 13: 41-47, 2003.

17. Philipp-Staheli J, Payne SR and Kemp CJ: p27(Kip1): regulation and function of a haploinsufficient tumor suppressor and its misregulation in cancer. Exp Cell Res 264: 148-168, 2001. 
18. Gao Y, Kitagawa K, Hiramatsu Y, et al: Up-regulation of GPR48 induced by down-regulation of p27Kipl enhances carcinoma cell invasiveness and metastasis. Cancer Res 66: 11623-11631, 2006.

19. Rodier G, Montagnoli A, DiMarcotullio L, et al: p27 cytoplasmic localization is regulated by phosphorylation on Ser10 and is not a prerequisite for its proteolysis. EMBO J 20: 6672-6682, 2001.

20. Ishida N, Hara T, Kamura T, Yoshida M, Nakayama K and Nakayama KI: Phosphorylation of p27Kip1 on serine 10 is required for its binding to CRM1 and nuclear export. J Biol Chem 277: 14355-14358, 2002.

21. Li S, Tokuyama T, Yamamoto J, Koide M, Yokota $\mathrm{N}$ and Namba H: Bystander effect-mediated gene therapy of gliomas using genetically engineered neural stem cells. Cancer Gene Ther 12: 600-607, 2005.

22. Chen J, Zhang ZG, Li Y, et al: Intravenous administration of human bone marrow stromal cells induces angiogenesis in the ischemic boundary zone after stroke in rats. Circ Res 92: 692-699, 2003

23. Nakayama K, Ishida N, Shirane M, et al: Mice lacking p27(Kip1) display increased body size, multiple organ hyperplasia, retinal dysplasia, and pituitary tumors. Cell 85: 707-720, 1996.

24. Nobes CD and Hall A: Rho GTPases control polarity, protrusion, and adhesion during cell movement. J Cell Biol 144: 1235-1244, 1999.

25. Besson A, Gurian-West M, Schmidt A, Hall A and Roberts JM: p27Kip1 modulates cell migration through the regulation of RhoA activation. Genes Dev 18: 862-876, 2004.
26. Aboody KS, Brown A, Rainov NG, et al: Neural stem cells display extensive tropism for pathology in adult brain: evidence from intracranial gliomas. Proc Natl Acad Sci USA 97: 12846-12851, 2000.

27. Li S, Gao Y, Tokuyama T, et al: Genetically engineered neural stem cells migrate and suppress glioma cell growth at distant intracranial sites. Cancer Lett 251: 220-227, 2007.

28. Xu G, Jiang XD, Xu Y, et al: Adenoviral-mediated interleukin-18 expression in mesenchymal stem cells effectively suppresses the growth of glioma in rats. Cell Biol Int 33: 466-474, 2009.

29. Ho IA, Chan KY, Ng WH, et al: Matrix metalloproteinase 1 is necessary for the migration of human bone marrow-derived mesenchymal stem cells toward human glioma. Stem Cells 27: 1366-1375, 2009.

30. Zhao D, Najbauer J, Garcia E, et al: Neural stem cell tropism to glioma: critical role of tumor hypoxia. Mol Cancer Res 6: 1819-1829, 2008.

31. Bexell D, Gunnarsson S, Tormin A, et al: Bone marrow multipotent mesenchymal stroma cells act as pericyte-like migratory vehicles in experimental gliomas. Mol Ther 17: 183-190, 2009.

32. Webb DJ and Horwitz AF: New dimensions in cell migration. Nat Cell Biol 5: 690-692, 2003.

33. Baldassarre G, Belletti B, Nicoloso MS, et al: p27(Kip1) stathmin interaction influences sarcoma cell migration and invasion. Cancer Cell 7: 51-63, 2005. 